This is the peer reviewed version of the following article: Adams, J. (2016).

Sustainability in Arts Education. International Journal of Art and Design Education, 35(3), 294-295, which has been published in final form at

https://doi.org/10.1111/jade.12126 This article may be used for non-commercial purposes in accordance with Wiley Terms and Conditions for Self-Archiving.

\title{
Editorial 35.3
}

\section{Sustainability in Arts Education} Jeff Adams

Sustainability has many and varied meanings, depending on the context of its usage, but is often associated with maintaining and enduring. In the case of education I would like to ally this with Dewey's profound remark that education should be, above all else, lifelong: the most important attitude that can be formed is that of desire to go on learning' $(1938,48)$. This concept seems as radical now as it was when first uttered in the 1930s, as many of our contemporary education systems (the UK in particular) hastily revert to short-term, instrumentalist models that eschew more substantive, civic conceptions of learning. Conversely, education considered from a longer view, one that holds social equality as a key notion in its progressive trajectory, parallels sustainability in the environment as manifest in the many projects that seek to harness natural resources without depleting them or producing toxic wastes, for the long-term benefit of all equally. The convergence of the thinking around progressive education and the environment is rooted in the common ground of sustainability, for this is one of the fundamental features of the 'good society', as Lawson \& Spours $(2011,7)$ put it:

... the concept of the Good Society is rooted in equality, democracy, sustainability and well-being, providing a vision and path of transformation capable of drawing support across different groups in an increasingly fragmented society.

At the heart of this convergence are the arts in education, since they are can be readily utilised to explore these complex but crucial notions of equality, democracy, and wellbeing, and sustainability in particular; thinking beyond the immediate, the pressing, to the larger issues of what it means to co-exist in a dynamic, precarious world of finite resources. The work of Arctic Sustainable Arts \& Design (ASAD 2016) is one example of the arts in education playing a fundamental role in young people's 
understanding and awareness of indigenous cultures and of the fragile eco systems on which they, and we, depend, while providing a platform for imaginatively rethinking the world and the way that we live in it.

Sustainability in the wider global context has increasingly required new political alignments, and this should not come as a surprise, given the corrosive social and environmental effects of rampant neoliberalism. Consequently those artists and arts educators with interests in sustainable practices find themselves on a political battlefield.

In the bleak aftermath of the UK's negative referendum on membership of the European Union, which, if nothing else, demonstrated how much more difficult it is to sustain long term collaborations than it is to wreck them, perhaps this is a moment to take stock and question those qualities of a society that we should value. The National Society for Education in Art and Design (NSEAD 2013, 1) touched on the long-term purpose of art education (in their valiant attempt to salvage depth and meaning from the Government's perfunctory attempt to rewrite the National Curriculum for England), with an insistence that art education endures to:

... enable pupils to contribute as confident citizens and future professionals to the culture, creativity, economic success, leisure, material and emotional wellbeing of our society within both national and global contexts.

Our 2015 conference, 'Sustainability in Arts Education', set out to discuss these matters and many more, and this issue of the Journal is devoted to invited papers from that event. The conference took place during November in Glasgow at the famous School of Art - in a fine new building, while restoration of the fire-damaged Macintosh building took place across the street. Delegates, drawn from around the world, voted for publication of the papers that impressed them most, many of which are included here. We also have three of the keynote papers which set the tone of the conference: Maddy Sclater's discussion of the relationship between technology enhanced learning and socio-ecological sustainability in arts education; Patricia McKinnon-Day's lecture on her artistic work that probes into social and cultural issues and exploring - or questioning - sustainable practices, sometimes in unexpected places, and Vicky Gunn's disquisition on the art school as the ground for producing 'prophetic nomads', social influencers able to imagine and innovate 
sustainable creative practices. Following these presentations the conference debated a wide range of issues on the sustainability theme, a selection of which fill the rest of these pages. One thing is certain: concerns about sustainability are likely to intensify over the coming years, and hopefully these discussions will help art educators and students to reconsider their practices within this enormously important sphere.

\section{References}

ASAD (2016) Arctic Sustainable Arts \& Design. Available at: http://www.asadnetwork.org/ (accessed August 3 2016).

Dewey, J. (1938) Experience and Education, London: Collier-MacMillan (reprinted 1969).

Lawson, N. and Spours, K. (2011) Education for the Good Society: The values and principles of a new comprehensive vision. London: Compass - Direction for the Democratic Left.

NSEAD (2013) Art and Design National Curriculum in England: DfE/NSEAD version. Available at: http://www.nsead.org/curriculumresources/downloads/PoS ART AND DESIGN DFE NSEAD combined versio n.pdf (accessed August 3 2016). 